\title{
CONTRIBUIÇÃO AO ESTUDO DE EFLUENTES DE INDÚSTRIAS DE CELULOSE E PAPEL
}

\section{CONTRIBUITION FOR THE STUDY IN THE EFFLUENTS FROM PULP END PAPER INDUSTRY}

\author{
Sonia Maria Bitencourt Frizzo ${ }^{1}$ Maria Cládis Mezzomo da Silva ${ }^{1}$ Celso Edmundo B. Foelkel $^{2}$
}

\section{R E S U M O}

O presente estudo descreve os tratamentos alternativos a que foi submetido o efluente secundário de uma indústria de celulose kraft branqueada. As amostras do efluente foram analisadas quanto ao teor de cloretos e de elementos-traço (zinco, cobre, chumbo e cádmio) e, a seguir, foram tratadas com sulfato de alumínio ou cloreto férrico, como floculantes, utilizando-se, ainda, resíduos sólidos do processo industrial ("dreg", "grit", cinza pesada) e carvão ativo, como auxiliares de floculação. Foi observada uma significativa redução do teor de cloretos e de elementos-traço nos efluentes finais, com o uso combinado de sulfato de alumínio/carvão ativo 2 e cloreto férrico/resíduos industriais, respectivamente.

Palavras-chave: Efluentes de indústria de celulose, elementos-traço, cloretos.

\section{S U M M A R Y}

The present study describes the alternative treatments applied to the secundary effluent of a bleached kraft process pulp industry. The effluent samples were analysed in relation to their contents of chloride and trace elements (zinc, copper, lead and cadmium), and submitted to a treatment with aluminium sulphate or iron chloride, as floculants, using further, solid residues of industrial process (dreg, grit and heavy ash) and active carbon, as coagulation adjuvants. A significant reduction of the contents of chloride and trace elements in the final effluent was observed by the combined use of aluminium sulphate/active coal 2 and iron chloride/industrial residues, respectively.

Key words: Effluents from pulp industry, trace elements, chloride.

1. Eng. Florestal, M.Sc., Professora Adjunta do Departamento de Química, CCNE. Universidade Federal de Santa Maria. 97119-900. Santa Maria. RS.

2. M.Sc., Técnico da Empresa Riocell S.A., Professor do Curso de Pós-Graduação em Engenharia Florestal, CCR. Universidade Federal de Santa Maria. 97119-900. Santa Maria. RS. 


\section{INTRODUÇÃO}

Segundo LEMOS et al. (1992), os efeitos tóxicos da descarga de efluentes industriais em mananciais hídricos devem ser intensamente investigados, uma vez que podem afetar a sobrevivência, o comportamento ou a composição genética dos organismos aquáticos, bem como a saúde da população, que busca nestes mananciais seu suprimento de água potável.

O conhecimento mais profundo das possíveis conseqüências do despejo de efluentes industriais em mananciais hídricos, em particular, tem motivado às empresas a investirem em programas com o fim de minimizar ou eliminar danos deste gênero, aos ecossistemas (SHIN et al., 1991).

Em uma indústria de celulose branqueada, o controle de cloretos faz-se necessário em virtude da utilização do cloro e do dióxido de cloro em um dos estágios da seqüência utilizada no branqueamento da polpa celulósica, sendo os efluentes dos primeiros estágios os que mais contribuem para a sua liberação (SÜSS et al., 1991 e GRIMVALL et al., 1991).

De acordo com AMAZARRAY (1992), os elementos-traço podem ser transportados na água sob a forma de espécies dissolvidas e/ou associadas a partículas sólidas. Os elementos-traço retidos no sedimento poderão ser novamente mobilizados por plantas e animais, tornando-se, pois, disponíveis para as cadeias alimentares. É, então, importante a determinação da concentração desses elementos nas frações lábeis disponíveis para o meio.

Assim sendo, investigou-se a viabilidade da aplicação no efluente secundário de tratamentos alternativos, em virtude de já terem demonstrado serem eficientes para redução de outros índices físico-químicos e organo halogenados (FRIZZO et al., 1993).

A utilização de sulfato de alumínio e de cloreto férrico, como agentes floculantes (AZEVEDO NETO, et al., 1976), coadjuvados por carvão ativo, no tratamento do efluente, complementa estudos preliminares (PERRICH, 1981).

Resíduos sólidos, de indústrias americanas de celulose, há algum tempo, vêm sendo utilizados como coadjuvantes de processos de tratamento de efluentes, com relativo sucesso (COOKSON, 1980).

\section{MATERIAL E MÉTODOS}

\section{Amostragem}

As amostras foram coletadas do transbordo do tratamento secundário da indústria RIOCELL S.A. e acondicionadas em recipientes plásticos, descontaminados, sendo posteriormente armazenadas em câmara fria (APHA AWWA, 1985 e AGUDO, 1987).

\section{Desenvolvimento}

O estudo dividiu-se em três etapas, todas elas realizadas a temperatura ambiente: caracterização geral do efluente; aplicação dos tratamentos ao efluente secundário; caracterização do efluente após os tratamentos (FRIZZO et al., 1993). 
Para a caracterização do efluente foram realizadas as determinações da concentração de cloretos e de elementos-traço (chumbo, cádmio, cobre e zinco).

Após a caracterização geral, necessária para conhecer-se a realidade do efluente, iniciou-se a aplicação de tratamentos com coadjuvantes/floculantes $\left[\mathrm{Al}_{2}\left(\mathrm{SO}_{4}\right)_{3}\right.$ e $\left.\mathrm{FeCl}_{3}\right]$ (AZEVEDO NETO et al., 1976) e adsorventes (carvão ativo 1, carvão ativo 2, "dreg", "grit" e cinza pesada). Imediatamente após, tomando-se o sobrenadante, realizou-se as determinações de cloretos e de elementos-traço (chumbo, cádmio, cobre e zinco), procedendo-se assim a terceira etapa do trabalho.

"Dreg" e "grit" são os resíduos sólidos provenientes de processo industrial, na recuperação do licor de cozimento; cinza pesada é o resíduo da queima do carvão mineral utilizado para geração de energia; carvões ativos 1 e 2 correspondem aos produtos Merck e Tanacarbo, respectivamente.

Nos ensaios de coagulação/floculação foram usadas soluções de sulfato de alumínio nas concentrações de 475 e $400 \mathrm{mg} / \mathrm{L}$, cloreto férrico com 200, 250 e $350 \mathrm{mg} / \mathrm{L}$. Como adsolventes, isto é, como auxiliares do tratamento, foram utilizados dois tipos de carvão 1 e 2 , nas concentrações de 100, 150 e $200 \mathrm{mg} / \mathrm{L}$; cinza pesada a 105 e 78,8 mg/L; "dreg" a 82,4 e 70,6 mg/L; "grit" a 78,3 e $58,2 \mathrm{mg} / \mathrm{L}$.

\section{Métodos de análise}

A concentração de cloretos foi medida segundo o método Argentimétrico indireto de Volhard (BACAN et al., 1985).

O teor de elementos-traço foi determinado por Espectrometria de Absorção Atômica (aparelho Perkin Elmer 3030), com forno de grafite HGA-400, amostrador automático AS-40 e impressora PR-100. Fez-se uso da técnica de adição sucessiva de padrões para todos os elementos analisados, bem como, de padrão certificado NIST (Estuarine Sediment Nr. 1646) (BETTINELLI et al., 1986).

Os tratamentos aplicados ao efluente constaram de 12 combinações entre coagulantes/floculantes e adsorventes: $\mathrm{FeCl}_{3}$, sem adsorvente; $\mathrm{FeCl}_{3}$ e "grit"; $\mathrm{FeCl}_{3}$ e "dreg"; $\mathrm{FeCl}_{3}$ e cinza pesada; $\mathrm{FeCl}_{3}$ e carvão $1 ; \mathrm{FeCl}_{3}$ e carvão $2 ; \mathrm{Al}_{2}\left(\mathrm{SO}_{4}\right)_{3}$, sem adsorvente; $\mathrm{Al}_{2}\left(\mathrm{SO}_{4}\right)_{3}$ e "grit"; $\mathrm{Al}_{2}\left(\mathrm{SO}_{4}\right)_{3}$ e "dreg"; $\mathrm{Al}_{2}\left(\mathrm{SO}_{4}\right)_{3}$ e cinza pesada; $\mathrm{Al}_{2}\left(\mathrm{SO}_{4}\right)_{3}$ e carvão $1 ; \mathrm{Al}_{2}\left(\mathrm{SO}_{4}\right)_{3}$ e carvão 2. Esta etapa foi realizada com o auxílio do teste do Jarro, onde foram colocados, respectivamente, o adsorvente, a amostra e o coagulante, corrigindo-se o pH para 4,7 [para $\mathrm{Al}_{2}\left(\mathrm{SO}_{4}\right)_{3}$ ] e 4,0 [para $\mathrm{FeCl}_{3}$ ], respectivamente. O programa de agitação foi realizado com auxílio de agitador mecânico, provido de jarro com capacidade de um litro, possuindo hélice de vidro com as dimensões $22 \times 15 \times 4 \mathrm{~mm}$ e constou de alta velocidade, $300 \mathrm{rpm}$ por minuto, seguindo-se 15 minutos à baixa velocidade, $50 \mathrm{rpm}$; depois disto, deixou-se em repouso por 30 minutos.

No sobrenadante resultante, determinaram-se valores de cloretos e da concentração de elementos-traço (cobre, zinco, chumbo e cádmio).

\section{Métodos estatísticos}

As análises estatísticas dos valores de cloretos foram feitas em uma primeira etapa através 
do teste de Kruskal-Wallis. A seguir, sempre que foi constatada diferença significativa, fez-se comparações dois a dois com o objetivo de isolar os tratamentos que apresentaram menores valores médios.

Após, empregaram-se medidas descritivas para explorar o comportamento estatístico de cada um dos grupos de tratamentos selecionado.

Posteriormente, passou-se a estudar a presença de associação estatística entre a classificação (grupo de tratamentos que apresentou o maior valor e o grupo de tratamentos que apresentou o menor valor) versus tipo de floculante empregado; classificação versus concentração de floculantes; classificação versus floculante/ presença ou ausência de adsorvente; classificação versus floculante/tipo de adsorvente.

A análise estatística de metais-traço foi descritiva, empregando-se média aritmética e amplitude total.

\section{RESULTADOS E DISCUSSÃO}

\section{Cloretos}

A média dos valores de cloretos do efluente, antes dos tratamentos propostos foi de 600 $\mathrm{mg} / \mathrm{L}$. De acordo com a SECRETARIA DA SAÚDE E DO MEIO AMBIENTE DO RIO GRANDE DO SUL (1989), valores inferiores a $500 \mathrm{mg} / \mathrm{L}$ de cloretos são os indicados para que o efluente proveniente de uma indústria de celulose e papel seja jogado no corpo receptor. Assim sendo, em todos os tratamentos com $\mathrm{Al}_{2}\left(\mathrm{SO}_{4}\right)_{3}$ a que foi submetido o efluente, encontrou-se valores médios de cloretos ao redor de 466,60 mg/L, o que caracteriza a eficiência deste coagulante/floculante.

Em relação aos diversos tipos de adsorventes utilizados, os tratamentos que conduziram a menores valores de cloretos foram com o uso de carvão ativo 2 . Havendo uma redução média acima de $22 \%$ quando o tratamento constou de sulfato de alumínio associado ao carvão ativo 2.

A Tabela 1 e a Figura 1 mostram as percentagens das concentrações de cloretos, de acordo com os tipos de tratamentos utilizados.

De acordo com a Tabela 1, os tratamentos com sulfato de alumínio são os que apresentaram o maior número de amostras com concentrações inferiores a $500 \mathrm{mg} / \mathrm{L}$.

O mesmo tipo de análise foi realizada para os coadjuvantes, sendo o carvão 2 o que demonstrou ser o melhor. 
TABELA 1: Distribuição relativa do número de amostras classificadas segundo o tipo de floculante e a concentração de cloretos em $\mathrm{mg} / \mathrm{L}$.

\begin{tabular}{l|c|c}
\hline \multicolumn{1}{c|}{ CLASSIFICAÇÃO } & \multicolumn{2}{c}{ FLOCULANTES (\%) } \\
\cline { 2 - 3 } & Sulfato de alumínio & Cloreto férrico \\
\hline $\begin{array}{l}\text { Proporção de amostras com concentrações } \\
\text { de cloretos e superiores a } 500 \mathrm{mg} / \mathrm{L}\end{array}$ & 0,00 & 51,43 \\
$\begin{array}{l}\text { Proporção de amostras com concentrações } \\
\text { de cloretos inferiores a } 500 \mathrm{mg} / \mathrm{L}\end{array}$ & 100,00 & 48,57 \\
\hline TOTAL & 100,00 & 100,00 \\
\hline
\end{tabular}

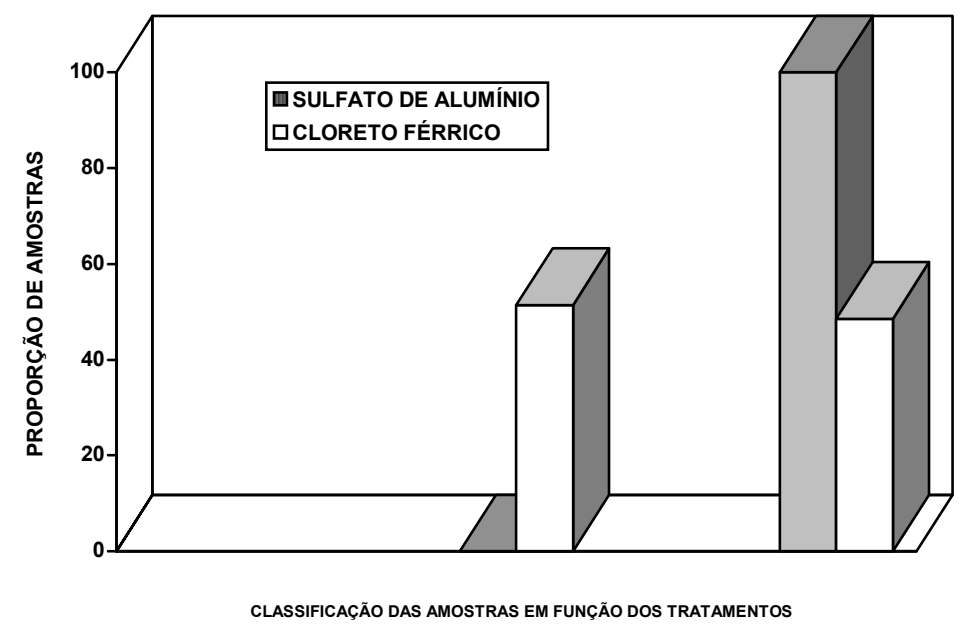

FIGURA 1: Distribuição relativa de amostras em função dos floculantes e da concentração de cloretos em $\mathrm{mg} / \mathrm{L}$.

\section{Elementos-traço}

As médias das concentrações de elementos-traço (ET) para o efluente sem tratamento foram $1,170 \mathrm{mg} / \mathrm{L}$ para o $\mathrm{Zn} ; 0,246 \mathrm{mg} / \mathrm{L}$ para o $\mathrm{Cu} ; 0,123 \mathrm{mg} / \mathrm{L}$ para o $\mathrm{Pb}$ e $0,006 \mathrm{mg} / \mathrm{L}$ para o $\mathrm{Cd}$.

Na Tabela 2 é ilustrado os resultados médios obtidos da determinação de zinco, cobre, chumbo e cádmio. 
TABELA 2: Resultados médios obtidos na análise de elementos-traço.

\begin{tabular}{l|c|c|c|c}
\hline \multicolumn{1}{c}{ TRATAMENTOS } & \multicolumn{3}{c}{ ELEMENTOS-TRAÇO (mg/L) } \\
\cline { 2 - 5 } & Zn & Cu & Pb & Cd \\
\hline Caracterização (efluente sem tratamento) & 1,170 & 0,246 & 0,123 & 0,006 \\
Sulfato de alumínio & 1,050 & 0,073 & 0,018 & 0,002 \\
Sulfato de alumínio + "dreg" & 1,768 & 0,158 & 0,014 & 0,002 \\
Sulfato de alumínio + carvão 1 & 0,886 & 0,103 & 0,016 & 0,003 \\
Sulfato de alumínio + carvão 2 & 0,727 & 0,038 & 0,028 & 0,002 \\
Sulfato de alumínio + "grit" & 1,958 & 0,028 & 0,017 & 0,002 \\
Sulfato de alumínio + cinza pesada & 1,743 & 0,056 & 0,020 & 0,001 \\
Cloreto férrico & 0,870 & 0,040 & 0,012 & 0,002 \\
Cloreto férrico + "dreg" & 0,624 & 0,040 & 0,005 & 0,002 \\
Cloreto férrico + carvão 1 & 1,174 & 0,057 & 0,012 & 0,001 \\
Cloreto férrico + carvão 2 & 0,988 & 0,087 & 0,007 & 0,001 \\
Cloreto férrico + "grit" & 0,985 & 0,034 & 0,012 & 0,001 \\
Cloreto férrico + cinza pesada & 0,796 & 0,029 & 0,016 & 0,002 \\
\hline
\end{tabular}

A amplitude total, resultante da diferença dos resultados obtidos em cada tratamento, encontra-se na Tabela 3.

TABELA 3: Amplitudes totais obtidas na análise de elementos-traço.

\begin{tabular}{l|ccc|c}
\hline \multirow{2}{*}{ TRATAMENTOS } & \multicolumn{4}{c}{ ELEMENTOS-TRAÇO (mg/L) } \\
\cline { 2 - 5 } & $\mathbf{Z n}$ & $\mathbf{C u}$ & $\mathbf{P b}$ & $\mathbf{C d}$ \\
\hline Caracterização & 0,032 & 0,001 & 0,019 & 0,002 \\
Sulfato de alumínio & 0,043 & 0,002 & 0,002 & 0,001 \\
Sulfato de alumínio + "dreg" & 0,274 & 0,004 & 0,003 & 0,001 \\
Sulfato de alumínio + carvão 1 & 0,008 & 0,001 & 0,001 & 0,000 \\
Sulfato de alumínio + carvão 2 & 0,008 & 0,001 & 0,004 & 0,000 \\
Sulfato de alumínio + "grit" & 0,022 & 0,001 & 0,002 & 0,000 \\
Sulfato de alumínio + cinza pesada & 0,007 & 0,000 & 0,005 & 0,000 \\
Cloreto férrico & 0,021 & 0,001 & 0,002 & 0,000 \\
Cloreto férrico + "dreg" & 0,027 & 0,002 & 0,004 & 0,001 \\
Cloreto férrico + carvão 1 & 1,174 & 0,000 & 0,001 & 0,000 \\
Cloreto férrico + carvão 2 & 0,037 & 0,000 & 0,002 & 0,000 \\
Cloreto férrico + "grit" & 0,000 & 0,000 & 0,002 & 0,000 \\
Cloreto férrico + cinza pesada & 0,003 & 0,002 & 0,001 & 0,001 \\
\hline
\end{tabular}

Analisando-se os resultados das Tabela 2 e 3, constata-se que no processo de caracterização obteve-se uma concentração média de $1,170 \mathrm{mg} / \mathrm{L}$ de zinco e uma variabilidade correspondente a $0,032 \mathrm{mg} / \mathrm{L}$ (amplitude total $=0,032$ ). De acordo com a Tabela 2, o tratamento que forneceu a 
menor concentração média de Zn foi o formado por cloreto férrico + "dreg", sendo que a dispersão não foi acentuada; aproximadamente $4,33 \%$ da concentração média, quando analisamos a Tabela 3 . Interpretações semelhantes podem ser obtidas para os demais tratamentos.

\section{CONCLUSÕES}

Face aos resultados obtidos, evidencia-se que:

a) O melhor coagulante/floculante testado para redução de cloretos foi sulfato de alumínio, na concentração de $350 \mathrm{mg} / \mathrm{L}$, coadjuvado por $100 \mathrm{mg} / \mathrm{L}$ de carvão ativo 2;

b) O melhor coagulante/floculante para redução de ET foi cloreto férrico, na concentração de $250 \mathrm{mg} / \mathrm{L}$, coadjuvado por resíduos sólidos industriais, nas concentrações de: $70,6 \mathrm{mg} / \mathrm{L}$ de "dreg", para o zinco e para o chumbo; 78,8 mg/L de cinza pesada, para o cobre; $58,2 \mathrm{mg} / \mathrm{L}$ de "grit", para o cádmio;

c) Houve redução do teor percentual de cloretos e de ET no decurso dos diversos tratamentos propostos, demonstrando a eficiência de quase todos os tratamentos;

d) A utilização de cloreto férrico como coagulante/floculante pode constituir fator de economia, uma vez que existe a possibilidade de ser produzido a partir do cloro e de minério de ferro, a baixo custo. Associado o seu uso, ao dos coadjuvantes residuais ("dreg", "grit" e cinza pesada), pode-se obter excelentes resultados, com menor gasto em insumos.

\section{REFERÊNCIAS BIBLIOGRÁFICAS}

AGUDO, E.G. Guia de coleta e preservação de amostras de água. São Paulo: CETESB, 1987. $150 \mathrm{p}$.

AMAZARRAY, M. T. R. A importância do estudo das formas de transporte e de transferência de elementos-traço para a avaliação ecotoxicológica. In: ENCONTRO DE ECOTOXICOLOGIA, II, 1992. Rio Grande. Anais... Rio Grande: Universidade Federal de Rio Grande, 1992. 101 p.

APHA AWWA. Standard methods for the examination of water and watstewater. Washington, 1985. 1268p.

AZEVEDO NETO, J.R., POVINELI, J., PARLTORE, A.C., HESPANOL, I., ROSSIN, A.C., YAGUINUMA,S. Técnica de abastecimento e tratamento de água. São Paulo, CETESB, 1976, v.2, 951p.

BACCAN, N., ANDRADE, J. C., GODINHO, O. E. S., BARORE, J. S. Química analítica quantitativa elementar. Campinas: Edgard Blücher Ltda., 1985. 259 p.

BETTINELLI, M., PASTORELLI, V., BARONI, U. STPF Determination of trace metals in fly ash samples. Athomic spectroscopy, Piacenza, 1986, v.7, n.2. p.45-48. 
COOKSON, J.T. Adsorption mechanisms: the chemistry of organic adsorption on activated carbon. In: CHEREMISINOFF, P.N.; ELLEBUSH, F. Carbon adsorption handbook. Michigan: Ann Arbor: 1980. p.241-279.

GRIMVALL, A., JONSSON, S., KARLSSON, S. et al. Organohalogens in unpolluted waters and larg bleach plant recipients. In: ENVIRONMENTAL CONFERENCE, 1991, Atlanta. Anais... Atlanta: Tappi Press, 1991, v. 1. p. 147-157.

FRIZZO, S.M.B., FOELKEL, C.E., MARTINS, A.F. Utilização de coadjuvantes de floculação alternativos no tratamento de efluentes de indústria de celulose Kraft. In: $26^{\circ}$ CONGRESSO ANUAL DE CELULOSE E PAPEL. Anais... São Paulo, 1993. p.581-588.

LEMOS, C. T., VARGA, V. M. F., HENRIQUE, J. A. P. et al. Avaliação genotóxica do rio Caí na área de influência do III Pólo Petroquímico. In: ENCONTRO DE ECOTOXICOLOGIA, II, 1992, Rio Grande. Anais... Rio Grande: Universidade Federal de Rio Grande, 1992. 101 p.

PERRICH, J.R. Activated carbon adsorption for wastwater treatment. Columbus, 1981. 252p.

SECRETARIA DA SAÚDE E DO MEIO AMBIENTE DO RIO GRANDE DO SUL. Norma Técnica SSMA no 1/89. Diário Oficial do Estado, Porto Alegre, 19 mar. 1989.

SHIN, N.H., SUNDARAM, M., JAMEEL, H. et al. Bleaching of softwood RDH pulp with low no chlorine bleaching sequences. In: ENVIRONMENTAL CONFERENCE. Anais... Atlanta: Tappi Press, 1991. v. 2, p.549-560.

SÜSS, H. U., NUMMERFROH, N., EUL, L.W., MEIR, J. Environmental aspects of short-sequence bleaching. Bleaching: A Tappi Press. Anthology, 1987-1990. Atlanta: Jamell, Hasan. 1991. p.482-492. 